\title{
Tuber shape and eye depth variation in a diploid family of Andean potatoes
}

\author{
Hannele Lindqvist-Kreuze ${ }^{1 *}$, Awais Khan ${ }^{1}$, Elisa Salas ${ }^{1}$, Sathiyamoorthy Meiyalaghan², Susan Thomson², \\ Rene Gomez ${ }^{1}$ and Merideth Bonierbale ${ }^{1}$
}

\begin{abstract}
Background: Tuber appearance is highly variable in the Andean cultivated potato germplasm. The diploid backcross mapping population 'DMDD' derived from the recently sequenced genome 'DM' represents a sample of the allelic variation for tuber shape and eye depth present in the Andean landraces. Here we evaluate the utility of morphological descriptors for tuber shape for identification of genetic loci responsible for the shape and eye depth variation.
\end{abstract}

Results: Subjective morphological descriptors and objective tuber length and width measurements were used for assessment of variation in tuber shape and eye depth. Phenotypic data obtained from three trials and male-female based genetic maps were used for quantitative trait locus (QTL) identification. Seven morphological tuber shapes were identified within the population. A continuous distribution of phenotypes was found using the ratio of tuber length to tuber width and a QTL was identified in the paternal map on chromosome 10. Using toPt-437059, the marker at the peak of this QTL, the seven tuber shapes were classified into two groups: cylindrical and non-cylindrical. In the first group, shapes classified as 'compressed', 'round', 'oblong', and 'long-oblong' mainly carried a marker allele originating from the male parent. The tubers in this group had deeper eyes, for which a strong QTL was found at the same location on chromosome 10 of the paternal map. The non-cylindrical tubers classified as 'obovoid', 'elliptic', and 'elongated' were in the second group, mostly lacking the marker allele originating from the male parent. The main QTL for shape and eye depth were located in the same genomic region as the previously mapped dominant genes for round tuber shape and eye depth. A number of candidate genes underlying the significant QTL markers for tuber shape and eye depth were identified.

Conclusions: Utilization of a molecular marker at the shape and eye depth QTL enabled the reclassification of the variation in general tuber shape to two main groups. Quantitative measurement of the length and width at different parts of the tuber is recommended to accompany the morphological descriptor classification to correctly capture the shape variation.

Keywords: Tuber shape, Eye depth, Morphological descriptors, Quantitative trait loci (QTL)

\section{Background}

Large variability in tuber appearance exists in the Andean cultivated potato germplasm. While wild potatoes are generally small and round with rather superficial eyes [1] the tubers of early-domesticated landrace cultivars are larger and have great variability in shape and eye depth [2]. Andean farmers seek to maintain this rich diversity by cultivating mixtures of landraces in their fields.

\footnotetext{
* Correspondence: h.lindqvist-kreuze@cgiar.org

'International Potato Center (CIP), Av. La Molina 1895, Apartado 1558, Lima 12, Peru

Full list of author information is available at the end of the article
}

Cultural rites, folk nomenclature, and the association of certain shapes with distinct culinary preferences and uses have been passed on through generations [2]. Thus, the user preferences that still persist in the original home of potato domestication are very distinct from those associated with potato in the areas that adopted this crop relatively recently. In modern varieties, superficial eyes, uniform color and round or oblong shape are preferential as these facilitate handling and processing. Heavy selection has consequently led to low diversity for these traits in modern cultivars.

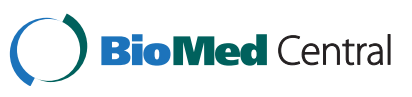

(C) 2015 Lindqvist-Kreuze et al.; licensee BioMed Central. This is an Open Access article distributed under the terms of the Creative Commons Attribution License (http://creativecommons.org/licenses/by/4.0), which permits unrestricted use, distribution, and reproduction in any medium, provided the original work is properly credited. The Creative Commons Public Domain Dedication waiver (http://creativecommons.org/publicdomain/zero/1.0/) applies to the data made available in this article, unless otherwise stated. 
For the purpose of revealing the genetic control of tuber shape and eye depth, various classification categories have been used, reflecting the variability present. Some studies featuring Solanum tuberosum (at either tetraploid or diploid level), have used two (round, long), three (round, oval and long), or four (round, oval, long oval, very long oval) shape categories [3-11]. In other cases, such as in a hybrid population between $S$. verrucosum and $S$. microdontum, six shape types were recorded (long, long oval, oval, round oval, round, compressed) [12]. In a $S$. phureja derived population, initially eight shape types were scored, but for genetic mapping they were grouped into three main classes (round, oval, long) $[13,14]$. Eye depth has previously been recorded using three $[10,14,15]$ to nine classes [11-13].

The International Potato Center (CIP) currently holds the largest biodiversity of cultivated potatoes. The morphological descriptors for tuber shape used by the CIP genebank include eight basic categories: compressed, round, ovoid, obovoid, elliptic, oblong, long-oblong and elongated, as well as an additional set of nine unusual shapes (for example pawlike). For eye depth, the scale has five classes: protuberant, superficial, slightly deep, deep and very deep [16].

The diploid backcross mapping population 'DMDD' was developed at CIP [17] and was used to anchor the first published potato genome sequence of potato (DM) and to develop a dense genetic map [18]. The female grandparent of the population, DM, belongs to the $S$. tuberosum Group Phureja [19] and the recurrent male parent, DI, to $S$. tuberosum diploid Andigenum Group Goniocalyx [20,21], thus providing some of the allelic variation present in the Andean landraces. DMDD segregates for numerous morphological, reproductive, physiological, biochemical and abiotic stress related traits $[22,23]$, which, combined with the high-density genetic map and the high-quality reference genome sequence, open up great opportunities for trait-QTL and gene discovery studies.

The present work was conducted to evaluate the utility of morphological descriptors for tuber shape to the identification of genetic loci responsible for the shape and eye depth variation. In addition, the reference genome sequence of potato was used to search for potential candidate genes responsible for the QTL effect found.

\section{Results}

\section{Phenotypic data}

Among the parental genotypes of DMDD, DM (CIP 801092) had elongated tubers with superficial eyes, DI (CIP 703825) had round tubers and deep eyes, and DMDI (CIP 305156.17) had elliptic tubers and slightly deep eyes (Fig. 1). Seven different shapes were found in the progeny in all trials, the most prevalent categories being obovoid, elliptic, oblong, long-oblong and elongated (Fig. 2, Table 1). The mean values in all experiments were quite similar for the ratio of tuber length to the width, but the distribution was skewed towards the smaller values in field 1 and field 2 trials (Fig. 3). Most progeny individuals had slightly deep or deep eyes, but there were also some individuals with very deep or superficial eyes (Table 1 ).

\section{Characteristics of parental genetic maps of DMDD}

Both parental maps had 12 chromosomes corresponding to the chromosomes of potato (Table 2). For the paternal map, the average chromosome length was $58.7 \mathrm{cM}$, the average marker interval was $1.9 \mathrm{cM}$ and contained an average of 29 markers giving a total of 339 markers. A total of 423 markers mapped on the maternal map with an average chromosome length of $65.4 \mathrm{cM}$, an average marker interval of $2.1 \mathrm{cM}$ and an average of 35 markers per chromosome. More details on the genetic map have been described by Khan et al. [23].

\section{Tuber shape and eye depth QTL}

QTL for the ratio of tuber length to width, general shape and eye depth were all found within the same region of chromosome 10 in the paternal map (Table 3, Table 4, Fig. 4). The largest-effect QTL was found for the ratio of

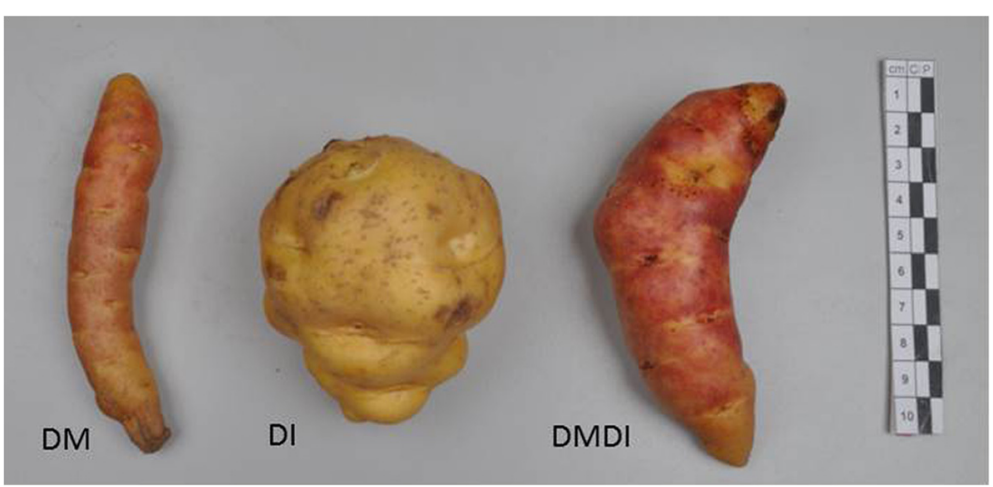

Fig. 1 Tuber shape and eye depth phenotypes of the DMDD population progenitors. The female grandparent, DM (CIP 801092), had elongated tubers with superficial eyes; the recurrent male parent, DI (CIP 703825), had round tubers and deep eyes; and DMDI (CIP 305156.17) had elliptic tubers and slightly deep eyes 


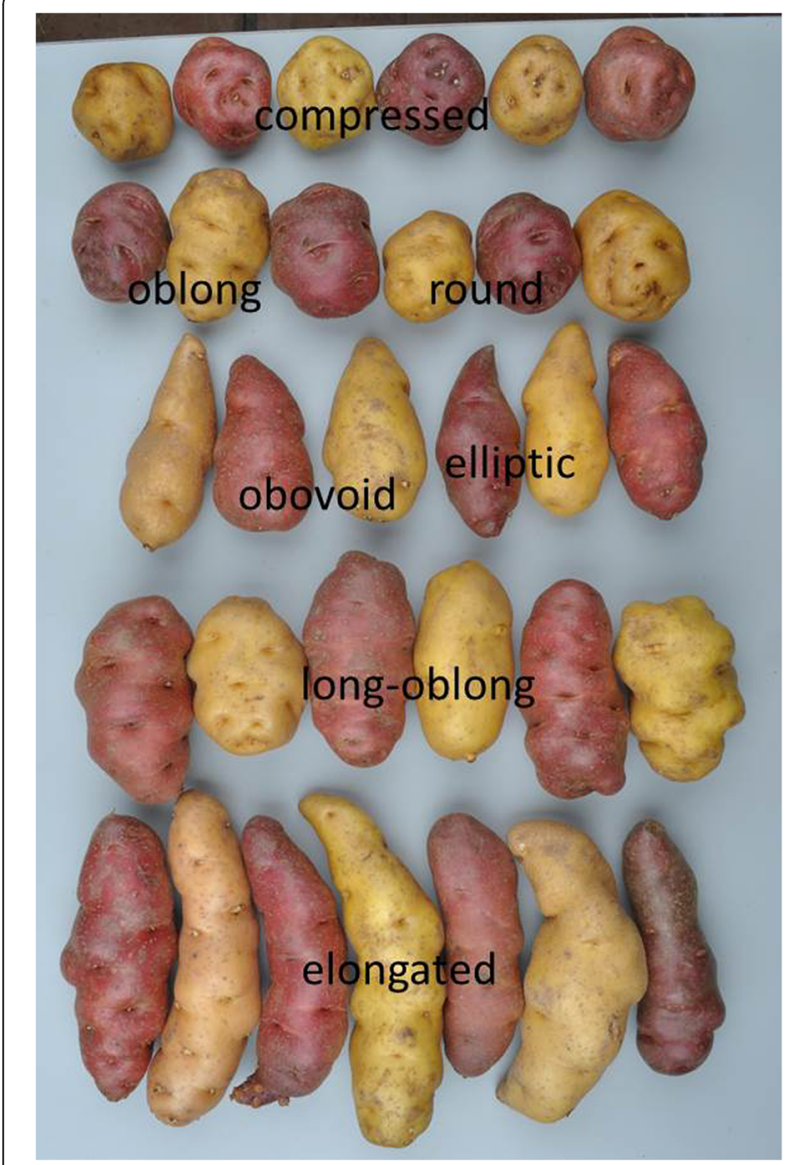

Fig. 2 Tuber shape and eye depth variation in the DMDD progeny in the trial field3. Seven different shapes: 'compressed', 'round', 'oblong', 'obovoid', 'elliptic', 'long-oblong' and 'elongated', were found in the progeny. The tuber heel is pointing up

tuber length to width in all experiments, regardless of planting material, growing conditions and environment, and explained between 37 and $40 \%$ of the variation (Table 3). The marker at the peak of this QTL is toPt437059 and the $\mathrm{np}$ allele from the DI parent is associated with the compressed, round, oblong and long-oblong shapes (Table 5). These shape classes have in common a cylindrical shape that has similar width throughout the whole tuber length. The individuals that lack the DI marker allele (thus are nn) have tubers that belong in the classes obovoid, elliptic and elongated, which have a markedly narrower base and/or apex as compared to the middle width (Table 5). The grouping of individuals is rather obvious in every class except for the field 3 trial, where unexpectedly many individuals were scored in the long-oblong class. Figure 5 depicts the overall relationship between the general shape and the ratio of the tuber length to the width.

The cylindrical tubers have more often very deep eyes compared to the non-cylindrical tubers, but both shape types have deep eyes (Table 5). In the maternal map, a small effect QTL for the ratio of tuber length to width and general shape was found in the same region on chromosome 5 but it was detected only in the trial field 2 (Table 3, Table 4). A QTL for eye depth was also found in chromosome 12 on the maternal map (Table 4).

\section{Candidate genes}

We identified a number of candidate genes underlying the significant QTL for tuber shape and eye depth (Additional file 1: Table S1). Pseudomolecule sequences corresponding to approximately $2 \mathrm{cM}$ at the QTL peaks by interval mapping in chromosomes 5, 10 and 12 were scanned for candidate genes. There were a total of 607 , 375 and 133 genes within the regions surrounding the QTL on chromosomes 5, 10 and 12 respectively. Many of the genes found in the QTL regions are annotated as hypothetical proteins and, for example, disease resistance genes. The most interesting gene families from the tuber shape and eye depth perspective belong to gene families associated with cell structure and function, including homeobox, expansin, extension and genes related to the production and modification of pectins (Additional file 1: Table S1). Homeobox genes POTH1 and a $B E L-1$ like gene were found at a distance of $1.94 \mathrm{Mb}$ and $1.37 \mathrm{Mb}$ from the QTL markers pPt650026 on chromosome 5 and toPt- 437059 on chromosome 10 respectively. Three members of the expansin gene family were also found in the region of significant QTL on chromosomes 5 and 10; $\beta$-expansin and expan$\sin$ were located at a distance of $1.03 \mathrm{Mb}$ and $1.12 \mathrm{Mb}$ respectively from the QTL marker PM0333_219 on chromosome 5 , and $\alpha$-expansin was located at a distance of $1.78 \mathrm{Mb}$ from the QTL marker -toPt-437059 on chromosome 10. Three extension genes were also identified within 1.11 Mb of the QTL marker PM0333_219 on

Table 1 Distribution of DMDD progeny individuals in general tuber shape and eye depth categories in the three field trials

\begin{tabular}{|c|c|c|c|c|c|c|c|c|c|c|c|}
\hline \multirow{2}{*}{$\begin{array}{l}\text { Trial (number of } \\
\text { progeny individuals) }\end{array}$} & \multicolumn{7}{|c|}{ General tuber shape } & \multicolumn{4}{|l|}{ Eye depth } \\
\hline & Compressed & Round & Obovoid & Elliptic & Oblong & Long-oblong & Elongated & Superficial & Slightly deep & Deep & Very deep \\
\hline Field1 $^{a}(n=134)$ & 0 & 7 & 22 & 27 & 30 & 23 & 25 & 8 & 40 & 54 & 20 \\
\hline Field2 $(n=148)$ & 1 & 1 & 27 & 26 & 34 & 35 & 24 & 2 & 47 & 74 & 25 \\
\hline Field3 $(n=117)$ & 10 & 2 & 30 & 3 & 25 & 40 & 7 & 0 & 41 & 75 & 1 \\
\hline
\end{tabular}

${ }^{1}$ eye depth was evaluated on only 122 individuals 


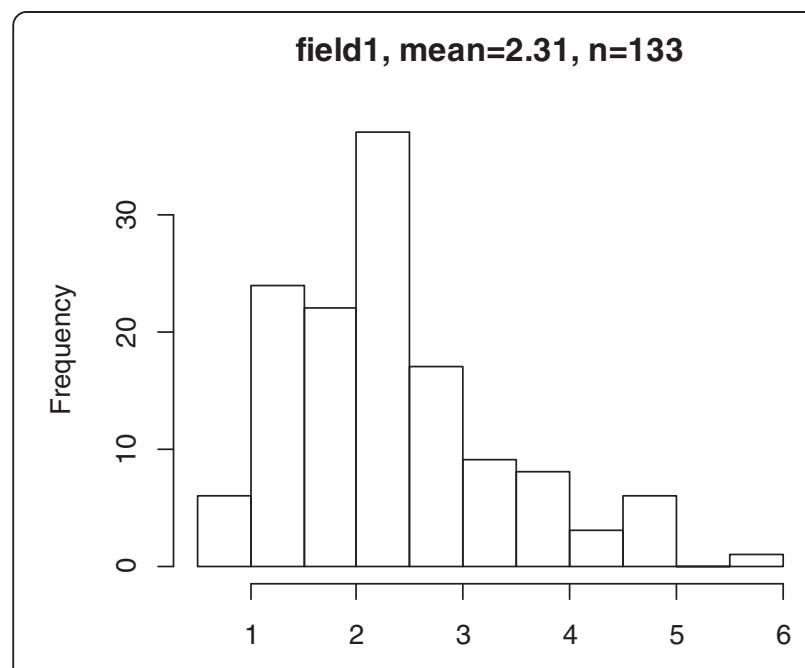

field2, mean=2.13, $n=146$

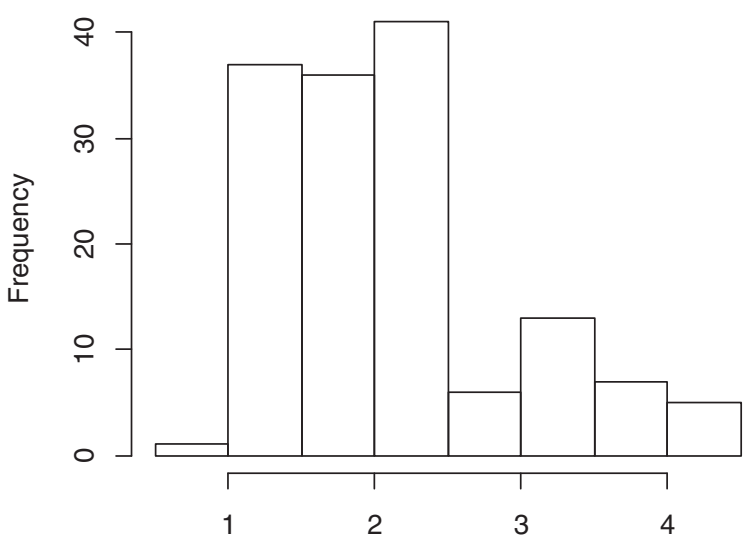

field3, mean=1.98, $n=117$

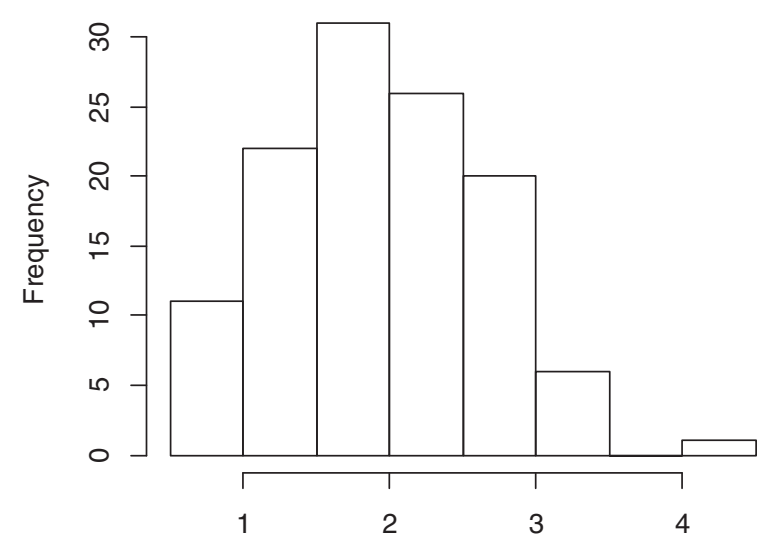

Fig. 3 The ratio of tuber length to width distribution in the DMDD progeny in the three field trials (field 1-3)

chromosome 5. Many genes related to the production and modification of pectins are found in the proximity of QTL markers pPt-650026 and PM0333_219 in chromosome 5, and toPt-437059 in chromosome 10. There are some notable transcription factor genes underlying the major chromosome 10 QTL marker toPt-437059, such as the GRAS transcription factor SCARECROW, and the AP2/ ERF domain-containing transcription factor, ERF5.

\section{Discussion}

Seven different shapes of tubers were found in the DMDD progeny according to the general tuber shape descriptors currently in use at the genebank of the International Potato Center. A continuous distribution of phenotypes was evident for the ratio of tuber length to width and a strong QTL for this trait was identified on chromosome 10 of the paternal map. With the help of the QTL marker toPt-437059, the seven tuber shapes were able to be classified into two groups: cylindrical and non-cylindrical. The shapes compressed, round, oblong and long-oblong, belonging to the first group, carry the marker allele originating from the recurrent male parent; while the shapes obovoid, elliptic and elongated form the second group and carry the marker allele of the female parent. The individuals with the marker allele from the male parent had significantly lower ratio of tuber length to width than the individuals with the female marker allele. The QTL is located in the same genomic region as the previously mapped dominant genes for round tuber shape [9] eye depth [10] and shape QTL [11]. The shape locus Ro (round tuber shape) on chromosome 10 is controlled by multiple alleles in $S$. tuberosum [9]. The alleles at the Ro locus in the native Andean diploids, such as DMDD progenitors S. tuberosum phureja and $S$. tuberosum goniocalyx may differ from those of $S$. tuberosum, resulting in variation not only in the tuber length, but also in the shape of the apex and the base. The shape variation in the native Andean potatoes is impressive, ranging from round to thin, while complicated paw-like and other shape types are also found. In all, there are 17 different tuber shapes recognized as formal morphological descriptors [16] but it is unknown whether all this variation can be explained by different alleles at the Ro locus. Recording general tuber shape descriptors in a wider base population and association mapping are required to test this hypothesis. While the major QTL on chromosome 10 plays the most important role in the classification of cylindrical and non-cylindrical tuber shape in DMDD, another minor QTL on chromosome 5 originating from the female parent also has an effect on tuber shape. This is consistent with other studies that report several other minor QTLs accounting for tuber shape variation [11-13, 24-26].

Round shape was found to be linked with deep eyes in studies involving diploid S. tuberosum $x$ S. phureja segregating populations [10,11]. In Andean potatoes deep eyes are also found in tubers that are long oblong. In the DMDD progeny, the longer tubers of non-cylindrical 
Table 2 Characteristics of the separate genetic maps of the DMDD population parents

\begin{tabular}{|c|c|c|c|c|c|}
\hline & Chromosome & Length of the linkage group (cM) & Number of markers & Mean marker interval (cM) & Max marker interval (cM) \\
\hline \multirow[t]{13}{*}{ Paternal map } & 1 & 57.71 & 35 & 1.70 & 12.84 \\
\hline & 2 & 64.30 & 44 & 1.50 & 21.36 \\
\hline & 3 & 59.88 & 26 & 2.40 & 16.52 \\
\hline & 4 & 73.65 & 26 & 2.95 & 15.83 \\
\hline & 5 & 39.90 & 14 & 3.07 & 14.20 \\
\hline & 6 & 57.56 & 23 & 2.62 & 9.15 \\
\hline & 7 & 60.45 & 31 & 2.02 & 18.20 \\
\hline & 8 & 54.15 & 24 & 2.35 & 17.25 \\
\hline & 9 & 72.31 & 45 & 1.64 & 12.86 \\
\hline & 10 & 62.29 & 23 & 2.83 & 21.47 \\
\hline & 11 & 43.21 & 26 & 1.73 & 7.37 \\
\hline & 12 & 59.01 & 22 & 2.81 & 10.56 \\
\hline & Total & 704.41 & 339 & & \\
\hline \multirow[t]{13}{*}{ Maternal map } & 1 & 85.11 & 66 & 1.31 & 15.48 \\
\hline & 2 & 63.07 & 39 & 1.31 & 12.49 \\
\hline & 3 & 87.37 & 52 & 1.71 & 24.73 \\
\hline & 4 & 85.13 & 30 & 2.94 & 19.81 \\
\hline & 5 & 54.82 & 10 & 2.51 & 12.75 \\
\hline & 6 & 63.31 & 39 & 1.67 & 5.47 \\
\hline & 7 & 66.80 & 29 & 2.39 & 14.16 \\
\hline & 8 & 55.30 & 34 & 1.68 & 11.14 \\
\hline & 9 & 34.22 & 27 & 1.27 & 8.42 \\
\hline & 10 & 64.99 & 53 & 1.25 & 9.87 \\
\hline & 11 & 57.34 & 29 & 2.05 & 10.49 \\
\hline & 12 & 67.55 & 15 & 4.82 & 22.99 \\
\hline & Total & 784.99 & 423 & & \\
\hline
\end{tabular}

type frequently had slightly deep and deep eyes, but tubers with cylindrical shape more often had deep and very deep eyes. Eye depth is influenced by the environment and, in addition, it may be difficult to visually distinguish slightly deep and deep eyes. However, in the DMDD progeny, very deep eyes were never found in the elliptic or obovoid individuals (non-cylindrical type), thus there may be a link between the apex/base shape and eye depth. Studies have suggested a major gene for eye depth in tuberosum based material [10, 14, 15]; however, what is considered deep eyes would not necessarily seem deep in the Andean material.

A single gene, eyd, was reputed to largely control eye depth $[10,14,15]$. The Eyd/eyd locus was mapped on chromosome 10 and deep eye was reported to be dominant [10]. Maris [15] first noted the link between the eye depth locus and the tuber shape locus. Ro and Eyd are tightly linked and separated by approximately $4 \mathrm{cM}$ [10]. In our study the LOD interval for the eye depth QTL is wider than that of the ratio for tuber length to

Table 3 QTL significant at 99\% genome-wide significance threshold, identified for the ratio of tuber length to width

\begin{tabular}{lllllcrr}
\hline Map & Trial & LOD & $\%$ & 2-LOD interval cM & Chromosome & Peak cM & Peak marker \\
\hline Paternal map & Field3 & 13.21 & 40.5 & $28.95-39.308$ & 10 & 32.545 & toPt-437059 \\
& Field2 & 15.07 & 37.8 & & & & \\
& Field1 & 13.64 & 37.6 & & & & \\
Maternal map & Field2 & 3.47 & 10.4 & $16.575-40.634$ & 5 & pPt-650026 \\
\hline
\end{tabular}


Table 4 Marker intervals with significant associations identified by Kruskal Wallis test for general tuber shape and eye depth

\begin{tabular}{|c|c|c|c|c|c|c|c|c|}
\hline Map & Chromosome & Trait & Trial & Interval $\mathrm{CM}^{\mathrm{a}}$ & Peak cM & Peak marker & K & P-value \\
\hline \multirow[t]{4}{*}{ Paternal map } & 10 & Eye depth & Field2 & $16.473-39.308$ & 32.545 & toPt-437059 & 33.018 & 0.0001 \\
\hline & & & Field1 & $16.473-39.308$ & 32.545 & toPt-437059 & 30.75 & 0.0001 \\
\hline & & & Field3 & $16.473-21.097$ & 21.097 & stsnp_c1_12035 & 11.879 & 0.001 \\
\hline & & General shape & Field1 & $15.221-39.308$ & 27.955 & pPt-539063 & 24.459 & 0.0001 \\
\hline \multirow[t]{2}{*}{ Maternal map } & 5 & General shape & Field2 & 23.943-42.069 & 32.808 & pPt-650026 & 19.501 & 0.0001 \\
\hline & 12 & Eye depth & Field2 & $29.089-44.555$ & 33.693 & pPt-459333 & 16.071 & 0.0001 \\
\hline
\end{tabular}

${ }^{1}$ Markers that have the significance level higher or the same as 0.001

width. The interaction of major genes with one or more modifier genes has been suggested as a reason for the intermediate phenotypes such as oval tuber shape and medium deep eyes [10]. Also minor QTL for eye depth have been identified $[12,13]$.

The effective management and exchange of crop germplasm relies on standard morphological and molecular descriptors. Morphological descriptors are also an essential element of systems for the testing of distinctness, uniformity, and stability (DUS) of new plant varieties. In a study of the practical utility of recommended potato descriptors for DUS of modern potato varieties, general potato shape was

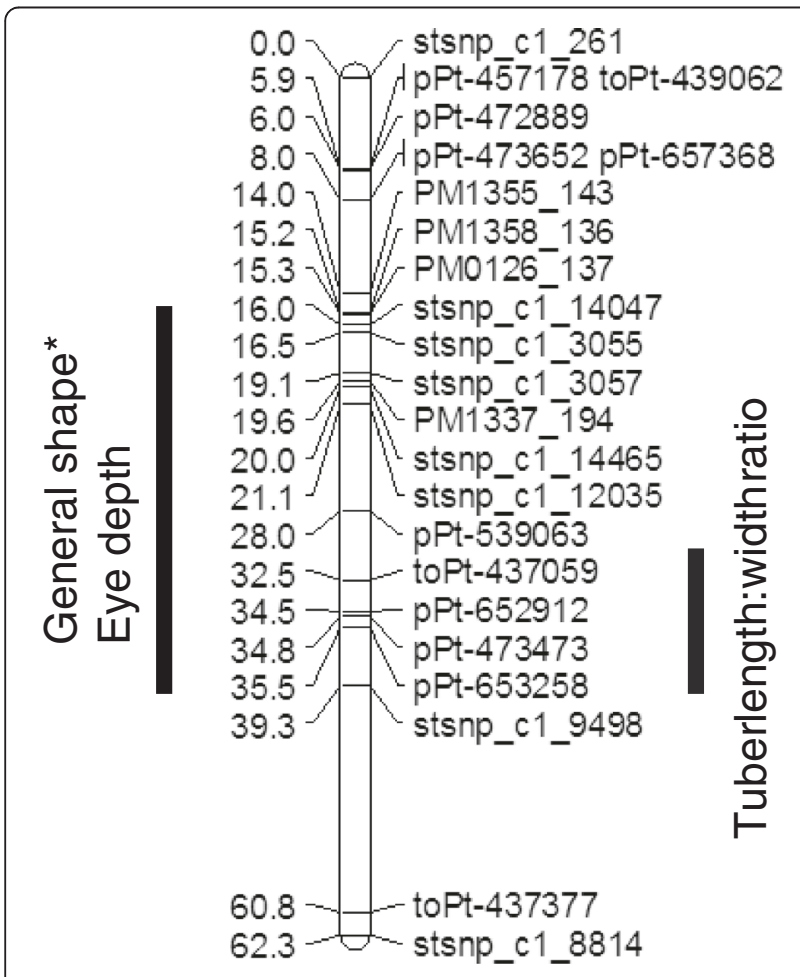

Fig. 4 Schematic representation of the QTL detected in chromosome 10 of the paternal genetic map. The marker locations on the linkage map are shown as cumulative distances in $\mathrm{CM}$. The right side of the linkage map shows the QTL for the ratio of tuber length to width obtained by interval mapping and the left side shows the Kruskall-Wallis confidence limits at $p<0.001$ for the eye depth and general shape QTL. *QTL for general shape was detected only in trial field 1 rejected as having high coefficient of variation between independent evaluators [27]. Data from qualitative measurements that include tuber width at the rose and heel ends could be used to improve the accuracy of the classification and to capture most of the variation in a bi-parental cross. However, in characterization of landrace collections expressing a much higher level of variability for tuber shape, the descriptors remain of high importance.

The elucidation of the reference potato genome sequence, including the annotation of around 39,000 protein-coding genes [28], has opened many avenues for the research community including the rapid identification of candidate genes underlying trait loci. In the significant QTL for shape and eye depth several gene families associated with cell structure and function in potato tubers were found. Homeobox genes that encode homeodomain proteins are transcription factors for several important genes in development [29] and KNOX and $B E L$ genes are primary members of the three amino acid loop extension (TALE) superclass of homeobox genes in plants [30]. The partnering of the BEL-1 like transcription factor StBEL5 and KNOX POTH1, has been shown to have a key role in tuber development [31-33]. Both BEL-1 and POTH1 are involved in biosynthesis of gibberellic acid [34], which is an important regulator of tuberization in potato [35]. Recently 14 BEL1-like genes in potato, including StBEL35 on chromosome 10, have been reported [36]. The $\alpha$-expansins and $\beta$-expansins are involved in cell-wall loosening, cell separation and cell expansion in tubers and stems $[37,38]$. Multiple gene families make up the extensin superfamily, such as the hydroxyproline-rich glycoproteins (HRGPs) which are abundant in cell walls of dicots [39, 40] and have been shown to have an involvement in wound healing in potato tubers [41]. Several studies have demonstrated the role of pectin-related genes in potato tuber development including the regulation of cell adhesion, expansion and differentiation, as well as cell-wall mechanical properties [41-44]. AP2/ERF proteins have been shown to play an important role in the regulation of a variety of biological processes related to growth and development in plants [45-47].

In summary, combining QTL mapping and comparative genomics we have identified a large set of potential candidate genes responsible for tuber shape and eye depth in potato. Fine mapping or association mapping is 
Table 5 Classification of the DMDD progeny individuals based on the marker toPt-437059 genotype, tuber shape and eye depth in the three field trials

\begin{tabular}{|c|c|c|c|c|c|c|c|c|c|c|c|c|c|}
\hline \multirow{2}{*}{\multicolumn{2}{|c|}{$\begin{array}{l}\text { ToPt-437059 } \\
\text { genotype/trial }\end{array}$}} & \multirow{2}{*}{$\begin{array}{l}\text { Tuber shape } \\
\text { Mean length: } \\
\text { width ratio (stdev) }\end{array}$} & \multirow[b]{2}{*}{ Compressed } & \multirow[b]{2}{*}{ Round } & \multirow[b]{2}{*}{ Obovoid } & \multirow[b]{2}{*}{ Elliptic } & \multirow[b]{2}{*}{ Oblong } & \multirow[b]{2}{*}{ Long-oblong } & \multirow[b]{2}{*}{ Elongated } & \multicolumn{2}{|l|}{ Eye depth } & \multirow[b]{2}{*}{ Deep } & \multirow[b]{2}{*}{$\begin{array}{l}\text { Very } \\
\text { deep }\end{array}$} \\
\hline & & & & & & & & & & Superficial & $\begin{array}{l}\text { Slightly } \\
\text { deep }\end{array}$ & & \\
\hline \multirow[t]{3}{*}{$\mathrm{nn}$} & Field1 & $2.73(0.77)$ & 0 & 0 & 18 & 16 & 1 & 8 & 19 & 0 & 25 & 37 & 0 \\
\hline & Field2 & $2.53(0.78)$ & 0 & 0 & 19 & 17 & 2 & 6 & 18 & 1 & 30 & 27 & 4 \\
\hline & Field3 & $2.36(0.52)$ & 0 & 0 & 25 & 3 & 4 & 24 & 6 & 0 & 25 & 37 & 0 \\
\hline \multirow[t]{3}{*}{$n p$} & Field1 & $1.6(0.48)$ & 0 & 5 & 1 & 2 & 20 & 13 & 0 & 2 & 2 & 23 & 14 \\
\hline & Field2 & $1.5(0.39)$ & 1 & 0 & 1 & 0 & 23 & 16 & 0 & 0 & 3 & 24 & 14 \\
\hline & Field3 & $1.43(0.50)$ & 8 & 2 & 1 & 0 & 18 & 11 & 1 & 0 & 10 & 30 & 1 \\
\hline
\end{tabular}

Only progeny individuals that were included in all experiments (in total 103) are included

required to narrow down the candidates for further functional studies and allele mining to implicate genes in potato tuber shape.

\section{Conclusions}

QTL in chromosome 10 largely controls tuber shape and eye depth in the bi-parental cross DMDD, which samples some of the shape variation present in the Andean native potatoes. Molecular marker at this QTL enabled the reclassification of the large variation spanning seven different shape classes to two main groups, cylindrical and noncylindrical, which reflect the ratio of tuber length to width. Morphological descriptor classification remains important in the characterization of the variable germplasm, but should be accompanied by the quantitative measurement of the length and width at different parts of the tuber to correctly capture the shape variation.

\section{Methods}

Plant Material, field and greenhouse evaluation

The diploid backcross population DMDD [17,18] ((DM X $\mathrm{DI}) \mathrm{X} \mathrm{DI}$ ) was developed by crossing the homozygous

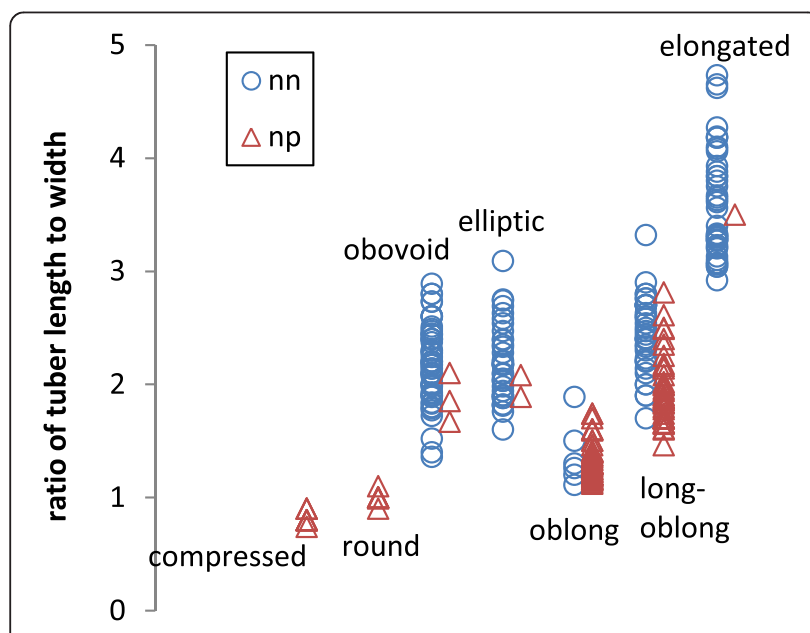

Fig. 5 The occurrence of the QTL peak marker toPt-437059 genotypes $\mathrm{nn}$ and $\mathrm{np}$ in categorical tuber shape classes
DM1-3 516 R44 as female with the heterozygous diploid $S$. tuberosum Stenotomum Group (formerly S. stenotomum ssp. goniocalyx accession CIP703825 (DI) as male, and backcrossing a resulting hybrid CIP305156.17 (DMDI) again with the DI as male parent. The progeny consists in total of 227 individuals, and of those 180 were used to construct the genetic map. The population was grown in three field trials: La Molina, Lima (field1, $\mathrm{n}=134$ ), San Agustin, Junin (field2, $\mathrm{n}=148$ ) and Acos, Pasco (field3, $\mathrm{n}=117$ ). Field1 trial was conducted in the central coastal desert between July 12 and November 15, 2011, while field2 and field3 trials were conducted in the central highlands from September 7, 2011 to January 20, 2012 and June 12 to November 8, 2012, respectively. All sites are located in Peru. Detailed information on soil type and climate in the trial sites is given in Table 6.

In field 1 and field 2 trials, in vitro plants were first planted in Jiffy $^{\mathrm{Tm}}$ strips and after 15 days they were planted in the field using an alpha lattice design [48] with two replications. Each genotype was represented by ten plants in each of the replicates. In the trial field3, second generation tubers were planted using the same design, but with three replications and 15 plants per genotype per replicate.

In all field trials the planting distance was $0.9 \mathrm{~m}$ between rows and $0.3 \mathrm{~m}$ between plants. All trials were irrigated: field 1 using irrigation canals, field 2 and 3 using sprinklers. The fields were fertilized at planting by applying $160 \mathrm{~kg} / \mathrm{ha}$ potassium chloride $(\mathrm{KCl}), 180 \mathrm{~kg} /$ ha phosphate $\left((\mathrm{NH} 4)_{2}\right.$ $\left.\mathrm{HPO}_{4}\right)$, and $100 \mathrm{~kg} /$ ha nitrogen $\left(\mathrm{CO}\left(\mathrm{NH}_{2}\right)_{2}\right)$. Nitrogen was applied a second time at the same dosage during the first hilling. Tubers were harvested when more than $75 \%$ of the plants had reached foliar senescence.

\section{Phenotypic evaluation and statistical analysis}

After harvest, tubers were washed, and fully developed tubers were selected for phenotypic evaluation. The general tuber shape was scored based on visual examination according to the morphological descriptors of Ortiz and Huaman [16], and each genotype was given a shape classification based on the average tuber shape. The scale consists 
Table 6 Detailed geographical location of the field trials and the characteristics of the soil and climate data recorded from the sites

\begin{tabular}{|c|c|c|c|c|c|c|c|c|c|c|c|c|c|c|}
\hline \multirow[t]{2}{*}{ Trial } & \multirow[t]{2}{*}{ Province } & \multirow[t]{2}{*}{ Locality } & \multirow{2}{*}{$\begin{array}{l}\text { Altitude } \\
\text { masl }\end{array}$} & \multirow{2}{*}{$\begin{array}{l}\text { Latitude } \\
\text { South }\end{array}$} & \multirow{2}{*}{$\begin{array}{l}\text { Longitude } \\
\text { West }\end{array}$} & \multicolumn{4}{|c|}{ Soil analysis } & \multicolumn{2}{|c|}{ Temperature ${ }^{\circ} \mathrm{C}$} & \multicolumn{2}{|c|}{ Relative humidity \% } & \multirow{2}{*}{$\begin{array}{l}\text { Total } \\
\text { precipitation mm }\end{array}$} \\
\hline & & & & & & S-S-C $\%$ & $\mathrm{OM}^{\mathrm{b}} \%$ & $\mathrm{pH}$ & $E C^{c}$ & Range & Mean & Range & Mean & \\
\hline Field1 & Lima & La Molina & 244 & -12.076289 & -76.948417 & $57-25-15$ & 1.3 & 7.4 & 4.3 & $12-25$ & 16.0 & $70-91$ & 85 & $<1$ \\
\hline Field2 & Junin & San Agustin & 3265 & -12.029167 & -75.244167 & $39-31-30$ & 1.6 & 7.5 & 0.4 & $1.6-30$ & 12.5 & $12-100$ & 78 & 332 \\
\hline Field3 & Pasco & Acos & 2612 & -10.766444 & -75.738361 & $66-16-18$ & 1.9 & 4.9 & 0.7 & $2.9-24$ & 13.5 & $14-91$ & 72 & 290 \\
\hline
\end{tabular}

${ }_{2}^{1}$ sand-silt-clay

2 organic matter

electric conductivity mmhos/cm 
of the following eight categories based on length and width at different parts of the tuber: compressed tubers are slightly wider than long; round and ovoid tubers are more long than wide and have a narrower apex (rose end) than base (heel end); obovoid tubers are longer than wide and have a narrower base; elliptic tubers have significantly narrower apex and base than the middle; oblong tubers have similar width at all parts of the tuber and are at maximum twice as long as wide; long-oblong tubers also have similar width at all parts of the tuber and their ratio of tuber length to width is between two and three; and elongated tubers are more than three times as long as wide. Eye depth was estimated by visual examination and classification into four classes: protuberant, superficial $(<2 \mathrm{~mm})$, slightly deep (2-4 mm), deep (5$6 \mathrm{~mm}$ ) and very deep (>6 mm).

Tuber shape was also measured as the ratio of tuber length to width by dividing the length $(\mathrm{mm})$ of the tuber from the base to the apex, by the width $(\mathrm{mm})$ at the middle of the tuber. For each genotype, the average of the ratio of tuber length to width from three tubers was used as the trait value. For tubers that clearly had a narrower base and/ or apex as compared to the middle, the width was also measured at the apex and the base. These measurements served for reinforcing the classification according to the above mentioned eight categories. Basic and multivariate analysis was performed in ' $\mathrm{R}$ ' [49]. Both qualitative and quantitative data were checked for outliers and distribution.

\section{Genetic map construction and QTL analysis}

Separate parental maps of 'DMDD' population were constructed using marker data previously developed by the Potato Genome Sequencing Consortium (PGSC) to construct genetic and physical maps for 'DMDD' [18]. Genetic maps were established for each parent separately as described by Khan et al.[23]. Briefly, map positions for all markers were extracted from the published map [18] and all markers with incomplete information (heterozygous in both parents and two alleles segregating) were excluded from the analysis. Markers that were heterozygous in the female parent and homozygous in the male parent were used to construct the maternal map, while the markers that were heterozygous in the male parent and homozygous in the female parent, were used to construct the paternal map. The map positions corresponding to [18] were used for parental maps after subtracting the map position of the first marker in cases where it was not ' 0 '. Therefore, the map positions, order of markers and interval between the markers is as presented by Sharma et al. [18]. Mapping was done using the 'CP' option of JoinMap 4 [50]. Phenotypic data for each experiment and male- female based genetic maps were used for QTL analysis using default options for interval mapping (IM) in MapQTL ${ }^{\circ}$ 6 [51]. Kruskal-Wallis test was performed for the categorical variables using default options in MapQTL ${ }^{\oplus} 6$
[51], while quantitative data were analyzed using interval mapping. A LOD threshold was determined using permutation test with 1000 permutations to declare a QTL genome-wide significant at $99 \%$ significance threshold. The marker toPt-437059 with the highest LOD value was used to validate the trait-QTL association. The progeny individuals were grouped according to the marker genotype (nn or $\mathrm{np}$ ) to compare the phenotypic data between the two groups.

\section{In silico identification of candidate genes}

Gene lists were extracted from the pseudomolecule within a region of approximately $+/-1 \mathrm{cM}$ of the significant QTLs, corresponding to +/- 1.31 Mb, +/- 1.25 Mb and+/$2.17 \mathrm{Mb}$ for chromosomes 10, 12, and 5, respectively. Gene lists were generated using the DM pseudomolecule AGPv4.3 build [18] and gene annotation v3.4 (http:// solgenomics.net/organism/Solanum_tuberosum/genome) [28].

\section{Additional file}

Additional file 1: Table S1. Gene lists were extracted from the pseudomolecule within a region of approximately $+/-1 \mathrm{cM}$ of the significant QTLs. Gene lists were generated using the DM pseudomolecule AGPV4.3 build (Sharma et al. 2013) and gene annotation v3.4 (http://solgenomics.net/ organism/Solanum_tuberosum/genome) (PGSC). Genes highlighted in bold have been specifically mentioned in the main manuscript. Genes highlighted in bold and italic are closer to the QTL markers.

\section{Competing interests}

The authors declare that they have no competing interests.

\section{Authors' contributions}

$\mathrm{HL}-\mathrm{K}$ analyzed and interpreted data and drafted the manuscript. AK constructed genetic maps and performed QTL analysis. ES performed the field experiments and coordinated data collection. SM participated in the field data collection, analyzed data and participated in writing the manuscript. ST performed in silico identification of candidate genes analysis. RG supervised the use of the morphological descriptors. MB conceptualized and planned the experiments. All authors read and approved the final manuscript

\section{Acknowledgments}

We thank Samantha Baldwin and Paul Johnston for comments on earlier drafts of the manuscript. We are also grateful to Marisol Durant and Fabiola del Villar for the technical assistance in the morphological characterization.

\section{Author details}

${ }^{1}$ International Potato Center (CIP), Av. La Molina 1895, Apartado 1558, Lima 12, Peru. ${ }^{2}$ The New Zealand Institute for Plant \& Food Research Limited, Private Bag 4704, Christchurch 8140, New Zealand.

Received: 11 February 2015 Accepted: 4 May 2015

Published online: 30 May 2015

\section{References}

1. Bradshaw JE. Quantitative genetics theory for tetrasomic inheritance. In: Bradshaw JE, Mackay GR, editors. Potato genetics. Wallingford, UK: CAB International; 1994. p. 71-107.

2. De Haan S: Potato diversity at height: multiple dimensions of farmer-driven in-situ conservation in the Andes. PhD thesis. The Netherlands: Wageningen University; 2009.

3. De Jong $H$, Burns V. Inheritance of tuber shape in cultivated diploid potatoes. Am J Potato Res. 1993;70:267-84. 
4. De Maine MJ, Fleming MLMH. The hybridisation of somatically chromosomedoubled dihaploid potatoes with tetraploid cultivars and the use of doubled dihaploids in genetic analysis of Solanum tuberosum. Ann Appl Biol. 1991;119:339-47.

5. Jong $H$, Rowe PR. Genetic markers in inbred clones of cultivated diploid potatoes. Potato Res. 1972;15:200-8.

6. Taylor LM. Variation patterns of parthenogenetic plants derived from "unreduced" embryo-sacs of Solanum tuberosum subspecies andigena (Juz. et Buk.) Hawkes. Theor Appl Genet. 1978;52:241-9.

7. Okwuagwu CO: Phenotypic evaluation and cytological analysis of 24chromosome hybrids for analytical breeding in potato. PhD thesis. Madison, Wl: University of Wisconsin; 1981.

8. Masson MF: Mapping, combining abilities, heritabilities and heterosis with $4 \times \mathrm{X}$ $2 x$ crosses in potato. PhD thesis. Madison, Wl: University of Wisconsin; 1985

9. van-Eck HJ, Jacobs J, Stam P, Ton J, Stiekema WJ, Jacobsen E: Multiple alleles for tuber shape in diploid potato detected by qualitative and quantitative genetic analysis using RFLPs. Genetics 1994, 137:303-309.

10. Li X-Q, De Jong H, De Jong DM, De Jong WS. Inheritance and genetic mapping of tuber eye depth in cultivated diploid potatoes. Theor Appl Genet. 2005;110:1068-73.

11. Prashar A, Hornyik C, Young V, McLean K, Sharma S, Dale MF, et al. Construction of a dense SNP map of a highly heterozygous diploid potato population and QTL analysis of tuber shape and eye depth. Theor Appl Genet. 2014;127:2159-71.

12. Śliwka J, Wasilewicz-Flis I, Jakuczun H, Gebhardt C. Tagging quantitative trait loci for dormancy, tuber shape, regularity of tuber shape, eye depth and flesh colour in diploid potato originated from six Solanum species. Plant Breed. 2008;127:49-55

13. Cuesta Subía X: Potato quality traits: variation and genetics in Ecuadorian potato landraces. PhD thesis. The Netherlands: Wageningen University; 2013.

14. Von Rathlef H, Siebeneick H. Über Einige Kreuzungen Eruanischer Sorten von Solanum andigenum Juz. et Buk. Mit Richters Jubel und Die Genetik von Schalenfarbe, Knollenfarbe, Fleischfarbe, Blütenfarbe und Knollenform Bei Der Kartoffel (On some crosses of Peruvian sorts of Solanum andigenum Juz. et Buk. with Richters Jubel and the genetics of colour of skin, tuber, flesh and flower colour and of tuber shape in the potato). Genetica. 1934;16:153-76.

15. Maris B. The modifiability of characters important in potato breeding Euphytica. 1966;15:18-31.

16. Ortiz R, Huaman Z: Inheritance of morphological and tuber characteristics. In: Potato genetics. Edited by Bradshaw JE, Mackay GR. Wallingford, UK: CAB International; 1994: 263-283.

17. Bonierbale $M$, Amoros W, Simon R: P4: towards public precision phenotyping of potato (P4). In: The 7th Solanaceae Conference: September 5-9 2010; Dundee, Scotland.

18. Sharma SK, Bolser D, de Boer J, Sønderkær M, Amoros W, Carboni MF, D'Ambrosio JM, de la Cruz G, Di Genova A, Douches DS et al:: Construction of reference chromosome-scale pseudomolecules for potato: Integrating the potato genome with genetic and physical maps. G3 2013, 3:2031-2047.

19. Paz MM, Veilleux RE. Influence of culture medium and in vitro conditions on shoot regeneration in Solanum phureja monoploids and fertility of regenerated doubled monoploids. Plant Breed. 1999;118:53-7.

20. Spooner DM, Nunez J, Trujillo G, Herrera MD, Guzman F, Ghislain M. Extensive simple sequence repeat genotyping of potato landraces supports a major reevaluation of their gene pool structure and classification. Proc Natl Acad Sci U S A. 2007;104:19398-403.

21. Ovchinnikova A, Krylova E, Gavrilenko T, Smekalova T, Zhuk M, Knapp S, et al. Taxonomy of cultivated potatoes (Solanum section Petota: Solanaceae) Bot J Linn Soc. 2011;165:107-55.

22. Khan A, Bonierbale M, Amoros W, Lindqvist-Kreuze H, Munive S, Salas E, et al. DMDD, a bi-parental resource population, holds great potential as a genetic discovery platform for complex traits in potato. China. 2013;2013.

23. Khan MA, Saravia D, Munive S, Lozano F, Farfan E, Eyzaguirre R, et al. Multiple QTLs linked toa agro-morphological and physiological traits related to drought tolerance in potato. Plant Mol Biol Rep. 2014;1-13.

24. Bradshaw J, Hackett C, Pande B, Waugh R, Bryan G. QTL mapping of yield, agronomic and quality traits in tetraploid potato (Solanum tuberosum subsp. tuberosum). Theor Appl Genet. 2008;116:193-211.

25. D'hoop B, Paulo M, Mank R, van Eck H, van Eeuwijk F. Association mapping of quality traits in potato (Solanum tuberosum L.). Euphytica. 2008;161:47-60.

26. D'hoop B, Keizer PC, Paulo MJ, Visser RF, van Eeuwijk F, van Eck H. Identification of agronomically important QTL in tetraploid potato cultivars using a marker-trait association analysis. Theor Appl Genet. 2014;127:731-48.
27. Gopal J, Kumar V, Pandey SK, Kumar R, Pande PC, Singh SV. Morphological descriptors for DUS testing of potato varieties. Potato J. 2007;34:59-60.

28. Potato Genome Sequencing Consortium. Genome sequence and analysis of the tuber crop potato. Nature. 2011:475:189-95.

29. Gehring WJ, Affolter M, Burglin T. Homeodomain proteins. Annu Rev Biochem. 1994:63:487-526.

30. Bürglin TR. Analysis of TALE superclass homeobox genes (MEIS, PBC, KNOX Iroquois, TGIF) reveals a novel domain conserved between plants and animals. Nucleic Acids Res. 1997;25:4173-80.

31. Banerjee AK, Lin T, Hannapel DJ. Untranslated regions of a mobile transcript mediate RNA metabolism. Plant Physiol. 2009;151:1831-43.

32. Chen H, Rosin FM, Prat S, Hannapel DJ. Interacting transcription factors from the three-amino acid loop extension superclass regulate tuber formation. Plant Physiol. 2003;132:1391-404.

33. Rosin FM, Hart JK, Horner HT, Davies PJ, Hannapel DJ. Overexpression of a knotted-like homeobox gene of potato alters vegetative development by decreasing gibberellin accumulation. Plant Physiol. 2003;132:106-17.

34. Chen H, Banerjee AK, Hannapel DJ. The tandem complex of BEL and KNOX partners is required for transcriptional repression of ga20ox1. Plant J. 2004;38:276-84.

35. Roumeliotis E, Kloosterman B, Oortwijn M, Lange T, Visser RGF, Bachem CWB. Down regulation of StGA3ox genes in potato results in altered GA content and affect plant and tuber growth characteristics. J Plant Physiol. 2013;170:1228-34.

36. Sharma P, Lin T, Grandellis C, Yu M, Hannapel DJ. The BEL1-like family of transcription factors in potato. J Exp Bot. 2014;65:709-23.

37. Cosgrove DJ. Loosening of plant cell walls by expansins. Nature. 2000;407:321-6.

38. Jung J, O'Donoghue EM, Dijkwel PP, Brummell DA. Expression of multiple expansin genes is associated with cell expansion in potato organs. Plant Sci. 2010;179:77-85.

39. Lamport DTA, Kieliszewski MJ, Chen Y, Cannon MC. Role of the extensin superfamily in primary cell wall architecture. Plant Physiol. 2011;156:11-9.

40. Showalter AM. Structure and function of plant cell wall proteins. Plant Cell. 1993;5:9-23.

41. Neubauer JD, Lulai EC, Thompson AL, Suttle JC, Bolton MD. Wounding coordinately induces cell wall protein, cell cycle and pectin methyl esterase genes involved in tuber closing layer and wound periderm development. J Plant Physiol. 2012;169:586-95.

42. Orfila C, Degan F, Jørgensen B, Scheller H, Ray P, Ulvskov P. Expression of mung bean pectin acetyl esterase in potato tubers: effect on acetylation of cell wall polymers and tuber mechanical properties. Planta. 2012;236:185-96.

43. Oxenbøll Sørensen S, Pauly M, Bush M, Skjøt M, McCann MC, Borkhardt B, et al. Pectin engineering: modification of potato pectin by in vivo expression of an endo-1,4- $\beta$-d-galactanase. Proc Natl Acad Sci U S A. 2000;97:7639-44.

44. Ross HA, Wright KM, McDougall GJ, Roberts AG, Chapman SN, Morris WL, et al. Potato tuber pectin structure is influenced by pectin methyl esterase activity and impacts on cooked potato texture. J Exp Bot. 2010;62:371-81.

45. Licausi F, Giorgi F, Zenoni S, Osti F, Pezzotti M, Perata P. Genomic and transcriptomic analysis of the AP2/ERF superfamily in Vitis vinifera. BMC Genomics. 2010;11:719.

46. Nakano T, Suzuki K, Fujimura T, Shinshi H. Genome-wide analysis of the ERF gene family in Arabidopsis and rice. Plant Physiol. 2006;140:411-32.

47. Sharoni AM, Nuruzzaman M, Satoh K, Shimizu T, Kondoh H, Sasaya T, et al. Gene structures, classification and expression models of the AP2/EREBP transcription factor family in rice. Plant Cell Physiol. 2011;52:344-60.

48. Patterson HD, Williams ER. A new class of resolvable incomplete block designs. Biometrika. 1976;63:83-92.

49. R: A language and environment for statistical computing [http://www.Rproject.org]

50. Van Ooijen JW. JoinMap 4, Software for the calculation of genetic linkage maps in experimental populations. Kyazma BV: Wageningen, The Netherlands; 2006

51. Van Ooijen JW. MapQTL 6, Software for the mapping of quantitative trait loci in experimental populations of diploid species. Kyazma BV: Wageningen, The Netherlands; 2009. 